\title{
Does Culicoides spp. (Diptera: Ceratopogonidae) Not Suck Human Blood in Riparian Habitat of a National Park
}

\author{
Ying-Hsi Lin', Meng-Tieh Yu1, Tzu-Wen Kuo', Ka-Iong Lam², Jeng-Tze Yang2,3* \\ ${ }^{1}$ Department of Medical Laboratory Science and Biotechnology, Yuanpei University of Medical Technology, Taiwan \\ ${ }^{2}$ Department of Entomology, National Chung Hsing University, Taiwan \\ ${ }^{3}$ Department of Entomology, Agriculture and Forestry University, Chitwan, Nepal \\ Email: ^jtyang@dragon.nchu.edu.tw
}

How to cite this paper: Lin, Y.-H., Yu, M.-T., Kuo, T.-W., Lam, K.-I. and Yang, J.-T. (2017) Does Culicoides spp. (Diptera: Ceratopogonidae) Not Suck Human Blood in Riparian Habitat of a National Park. Advances in Entomology, 5, 93-98. https://doi.org/10.4236/ae.2017.53009

Received: April 25, 2017

Accepted: July 10, 2017

Published: July 13, 2017

Copyright $\odot 2017$ by authors and Scientific Research Publishing Inc. This work is licensed under the Creative Commons Attribution International License (CC BY 4.0).

http://creativecommons.org/licenses/by/4.0/

\begin{abstract}
Is the wild animal conservation result in Taiwan good enough to provide the blood resources for the blood sucking insect and cause the insect behavior changed? Based on the bimonthly investigation of Culicoides sp. in Wuling area, Sheipar National Park, by both human bait method and light trap method, we found that there were totally 13,191 individuals trapped by light trap and collected but no one single Culicoides sp. trapped by human bait during the study period of Wuling Long Term Ecological Research (WLTER) in 2012. Two of the three sites were recorded and reported as the midge attacked the ranger and tourists of Sheipa National Park in 2010 and 2011 respectively. Along with the study of WLTER some wild animals encounter more often than before, especially the bird population in the riparian ecosystem of the mountain river Chi Chia Wan Stream. On the other end, Culicoides sp. preferred to the blood of birds and amphibians as well as mammals according to the article review. So, the effectiveness of blood resource from wild animals may cause the behavior of blood sucking insect like as Culicoides sp. shifted to or returned back to the original and the favorite blood resource.
\end{abstract}

\section{Keywords}

Culicoides, Human Bait Method, Light Trap Method, Blood Resource

\section{Introduction}

The range of altitudes of Wuling area in Sheipa National Park is from 1740 to 2500 meters above sea level. The research team started investigating the riparian insect community at the mountain river Chi Chia Wan Stream of Wuling area since 2004; at 2011, there are a total number of 24 orders 190 families and 
177,887 individuals of insects collected in this area. After identification and analysis, the results showed that Diptera is the most dominant group of insects with the most amounts; its sum is 51 families 100,018 individuals which is $56.23 \%$ of the total number [1]. In 2012, besides the continuous investigation in the WLTER common sites, we have also conducted an investigation specifically on the blood feeding Culicoides spp. (Diptera: Ceratopogonidae) based on two separated reports of midge attack incidents, one of which was reported by one of the team members in 2010 at the \#3 Dam II station (Figure 1) of Chi Chia Wan Stream and the other one was by tourists in 2011 near Chaofeng bridge.

Chen [2] has recorded 60 species of Culicoides spp. originated in Taiwan, both inland and offshore islands such as Penghu Islands, Orchid Island, Green Island, and Hsiao Liuqiu Island, etc. According to the collection records from Taiwan, Culicoides spp. are mainly bloodsucking on livestock and there are very few reports that sucking on human. Furthermore, Culicoides spp. are the main vector for the bovine ephemeral fever which prevails in spring (March, and April) and in fall (September and October)each year around the cattle range [3]. The most typical case is $C$. arakawae served as vector for the leucocytozoonosis [4]. However, in China there are $C$. pulicaris that feed on human blood; in South

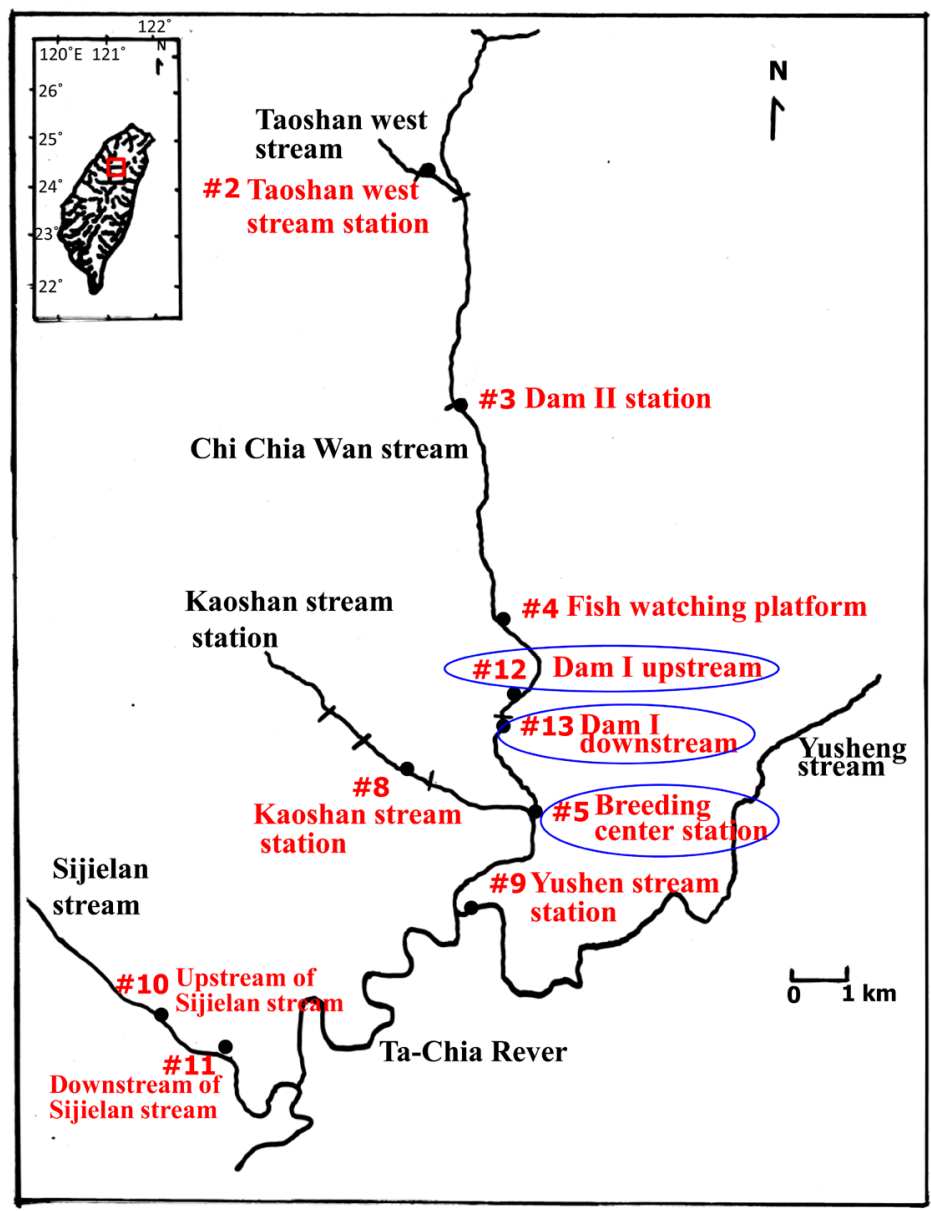

Figure 1. The investigation stations are at WLTER in Wuling area, Sheipar National Park. 
Pacific there are records of $C$. belkini biting human [5]. C. grahamii in Africa and $C$. austeni in South America are vectors of Acanthocheilonemaperstans. $C$. grahamii is also vector for Mansonella streptocerca. And C. urens in South America is vector for Mansonella ozzardi [6].

Culicoides spp. are just like mosquitoes, only female individuals would feed on blood in order to carry fertilized eggs. Although there are no records showing Culicoides as vectors for serious human disease, female bites can cause extreme itchiness for human, and there is possibility that excessive scratching may be infected or deteriorated and lead to dermatitis or even Anaphylactic shock. Therefore, we have added an investigation on Culicoides as we carry out the WLTER in 2012. As a result, we have found that there are Culicoides in Wuling area, and we put together the data from Culicoides investigation in 2012 for future references.

\section{Materials and Methods}

The original long term ecological research in Wuling area is a bimonthly investigation, from 7:30 to 19:30, we set up and retreat multiple ecological collecting traps [7] from the eight locations along Chi Chia Wan Stream (Figure 1). The catchment located at Wuling area, Sheipar National Park, central Taiwan. The annual precipitation is $1642 \mathrm{~mm}$ in average, the dry season with mean monthly rainfall less than $40 \mathrm{~mm}$ (October to next February), and frequently exceeding $300 \mathrm{~mm}$ during the wet season (May to September). The longitude and latitude of the study area is situated at $24^{\circ} 23^{\prime} \mathrm{N}, 121^{\circ} 18^{\prime} \mathrm{E}$ and denoted both in Figure 1 and in the text as well according to our previous work [8].

For this investigation which dated from January to December of 2012, we added human bait method during the day time, trapping Culicoides for $10 \mathrm{mi}$ nutes each time on each of the eight locations: station \#2, \#3 \#4, \#12 and \#13, \#8, \#5 and \#9 (Figure 1). Detail situation of each station is noted as our previous paper about the prey of Taiwan Landlocked Salmon [9]. On the other hand, we also used light trap method on three of the locations only: \#12,\#13 and \#5, to set the light trap for collecting Culicoides from 16:00 to 22:00. Although restricted by power supply, we managed to extend the power chords and set up trapping lights on the trees as close to the waterside of Chi Chia Wan Stream as possible. All the samples we collected are preserved in $75 \%$ alcohol and brought back to the lab to examine under microscope. The individual number counted after identification and basic analysis for comparing the difference of the number changed during the investigation period. The identification of the genus Culicoides based on the previous works Chen [2] and $\mathrm{Yu}$ [10].

\section{Results}

The result of human bait method at all eight locations in Wuling area is zero, while all three locations using light trap method have collected a total of 13,191 individuals of in April, June, August and October. Of the three locations, we have collected the most Culicoides in \#13, a total of 7337; in \#5 we collected the 
least, only 1715 individuals (Table 1).

The monthly collection of Culicoides was the highest in June, and the total number of all three stations was 6606, but not in February and December. The highest amount of Culicoides collection in single station in single month was found at \#13 in June, the total number is 5723 (Figure 2).

\section{Discussion}

This study started investigating the insect community at the mountain river Chi Chia Wan Stream of Wuling area since 2004, based on the long term ecological monitoring project of Sheipar National Park. It is the issue of land locked salmon conservation and preservation in Taiwan. Some cases of Culicoides attacked park ranger and tourist happened in 2010 and 2011. The study applied the human baiting trap to investigate the population at 2012 for one year.

Comparing to the Forcipomyia taiwana and other Ceratopogonidae midges, Culicoides is obviously larger in size. In addition, the wing stigmata are a significant diagnostic character for identifying the Culicoides midges from others. According to Capinera [11] the Culicoides prefers to lay eggs in moisture soil and larvae are aquatic or semi-aquatic. All the investigation station along with the

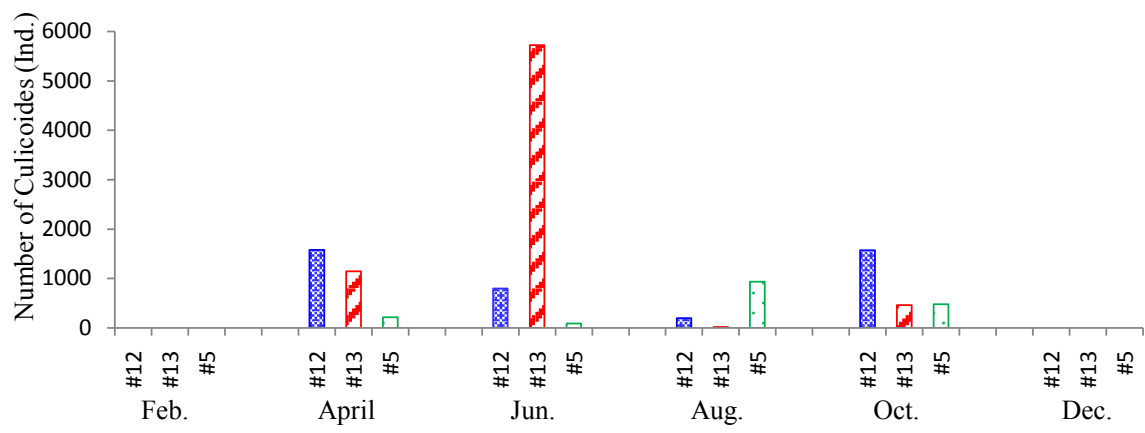

Figure 2. The insect numbers of Culicoides sp. bimonthly collected by light traps on three stations $(\# 12,13,5)$ of Wuling area in 2012.

Table 1. The Culicoides adult attracted by human bait method and light trap method at the stations of Wuling area in 2012.

\begin{tabular}{ccc}
\hline \multirow{2}{*}{ Station } & \multicolumn{2}{c}{ No. of Culicoides adult } \\
\cline { 2 - 3 } & Human bait method & Light trap method \\
\hline$\# 2$ & 0 & - \\
$\# 3$ & 0 & - \\
$\# 4$ & 0 & 4139 \\
$\# 12$ & 0 & 7337 \\
$\# 8$ & 0 & - \\
$\# 5$ & 0 & 1715 \\
$\# 9$ & 0 & - \\
\hline
\end{tabular}

-: uncheck. 
river as riparian habitat [7] just meet the environmental quality for Culicoides. The swarmed Culicoides attacked our team member in 2010. It was not happened until the time during 17:00-18:00 at the \#3Dam II station. So, that is the reason why we decided to investigate after sunset. It is the active time period for the Culicoides midges. Based on Chiu [3] a study from the animal farm, the majority of active time periods are dusk and dawn; it is not common as whole day active. And we only think about the time period after sunset because of the reason that we have to compare with light trap at a time.

Among 8 stations insect collected a total of 13,191 individuals of in April, June, August and October. But there is no insect collected in both February and December. It may be because of the low temperature in the $1800 \mathrm{~m}$ high mountain. Of the three locations, we have collected the most Culicoides in \#13, a total of 7337; in \#5 we collected the least, only 1715 individuals by light trap (Table 1). It is to say the Culicoides occurred in Wuling is true. And the population obviously increases from April to June at station \#3. However, the population sudden decreased in August besides of that in \# 5. It may be caused by the typhoon SAOLA (no. 1209) attacked Taiwan from July $31^{\text {st }}$ to August $3^{\text {rd }}$. The typhoon SAOLA made soil, mud, rock and fallen tree or log altogether flashed down by the flooding conducted by $1200 \mathrm{~mm}$ super heavy precipitation. And the result caused the river bed land scape changed and a lot of massive reformed of the riparian ecological system. The habitat of Culicoides also changed naturally in this situation. Until October, the changed landscape making some small water bodies preserved some larvae of Culicoides.

As it is just revealed by the above collected insect by light trap that the Culicoides midges actually existed in Wuling area. However, there is no more biting record in the area after 2012. The interpretation to these cases pointed to 1 . The investigating time point may be not exactly after sunset, but still cove the time period of the major active time period. So, that the Culicoides midges completely absent by the human bait method is unusual situation. 2. The population decreased and disappeared caused by the flooding and the riparian landscape changed. The potential habitat removed may be the key factor of the population perished. 3. According to the reference articles, Culicoides midges preferred more to suck the blood of wild animals than to that of human [12]. It is worth to note about the Culicoides not sucking human blood. After all, the study undergoes in Sheipar National Park where the wild animal conservation is better than other place. And there is no Culicoides midge attracted by human bait method.

\section{Acknowledgements}

We would like to present our appreciation to whom has helped in the investigation project. They are Hsing Hau Wang, and Ya Yuan Wang. The financial support by the project no. PG 10012-0330 is also appreciated.

\section{References}

[1] Lin, H.J., Wang, C.W., Wu, S.H., Kuan, W.H., Shao, K.T., Sun, Y.H., Kuo, M.H., 
Tzeng, C.S., Yang, J.T., Yeh, C.H., and Tsai, S.T. (2011) Long-Term Ecological Monitoring and Modeling in the Streams of the Wuling Area. Commissioned Research Report, Shei-Pa National Park Headquarters, Taiwan, 734 p. (In Chinese)

[2] Chen, C.S. (1984) Taxonomic Study on the Genus Culicoides (Diptera, Ceratopogonidae) in Taiwan. PhD Dissertation, National Taiwan University, Taiwan, 226 p. (In Chinese)

[3] Chiu, T.I. (2011) Occurrence of the Biting Midges, Culicoides spp. (Diptera: Ceratopogonidae) in Animal Farms. Master Thesis, National Chung Hsing University, Taiwan, 46 p. (In Chinese)

[4] Yu, C.Y. (2001) Culicoides arakawae Population Succession and Blood-Feeding Factors in Relation to Leucocytozooncaulleryi Transmission. PhD Dissertation, National Chung Hsing University, Taiwan, 165 p. (In Chinese)

[5] Chow, C.Y., Lien, J.C. and Wang, C.H. (1999) Medical Entomology. Nan Sang Tang Publishing Company, Taiwan, 536 p. (In Chinese)

[6] Service, M. (2012) Medical Entomology for Students. 5th Ed., Cambridge University Press, Cambridge, 317 p. https://doi.org/10.1017/CBO9781139002967

[7] Yang, J.T. and Yeh, W.B. (2007) Oncorhynchusmasouformosanus and Its Neighbors-The Insect Communities in Waterfront Land. Science Development, 417, 1922. (In Chinese) http://203.145.193.110/NSC_INDEX/Journal/EJ0001/9609/9609-04.pdf

[8] Lin, H.J., Peng, T.R., Cheng, I.C., Chen, L.W., Kuo, M.H., Tzeng, C.S., Tsai, S.T., Yang, J.T., Wu, S.H., Sun, Y.H., Yu, S.F. and Kao, S.J. (2012) Trophic Model of the Subtropical Headwater Stream Habitat of Formosan Landlocked Salmon, Oncorhynchusformosanus. Aquatic Biology, 17, 269-283. https://doi.org/10.3354/ab00481

[9] Yang, I.H., Liao, L.Y., Onozato Hiroshi, Huang, Y.S., and Yang, J.T. (2012) The Component of Stomach Content and the Characteristic of Prey in Taiwan Landlocked Salmon (Oncorhynchusmasouformosanus) from Cijiawan Stream, Wuling, Central Taiwan. Formosan Entomology, 32, 317-330. (In Chinese, with English Abstract)

[10] Yu, Y.X. (2005) Ceratopogonidae of China, Insecta, Diptera Vol. II. Military Medical Science Press, Beijing, 815-1699. (In Chinese)

[11] Capinera, J.L. (2008) Encyclopedia of Entomology. 2nd Ed., Springer Science \& Business Media, Heidelberg, 2061 p. https://doi.org/10.1007/978-1-4020-6359-6

[12] Lassen, S.B., Nielsen, S.A. and Kristensen, M. (2012) Identity and Diversity of Blood Meal Hosts of Biting Midges (Diptera: Ceratopogonidae: Culicoides Latreille) in Denmark. Parasit Vectors, 5, 143-151. https://doi.org/10.1186/1756-3305-5-143 
Submit or recommend next manuscript to SCIRP and we will provide best service for you:

Accepting pre-submission inquiries through Email, Facebook, LinkedIn, Twitter, etc. A wide selection of journals (inclusive of 9 subjects, more than 200 journals)

Providing 24-hour high-quality service

User-friendly online submission system

Fair and swift peer-review system

Efficient typesetting and proofreading procedure

Display of the result of downloads and visits, as well as the number of cited articles Maximum dissemination of your research work

Submit your manuscript at: http://papersubmission.scirp.org/

Or contact ae@scirp.org 